\title{
Influence of conductive polymer doping on the viability of cardiac progenitor cells $\uparrow$
}

Cite this: J. Mater. Chem. B, 2014, 2 , 3860

Received 24th January 2014 Accepted 8th April 2014

DOI: $10.1039 / c 4 t b 00142 g$

www.rsc.org/MaterialsB

\author{
A. Gelmi, ${ }^{* a}$ M. K. Ljunggren, ${ }^{\text {b }}$ M. Rafat ${ }^{\text {bc }}$ and E. W. H. Jager ${ }^{a}$
}

Cardiac tissue engineering via the use of stem cells is the future for repairing impaired heart function that results from a myocardial infarction. Developing an optimised platform to support the stem cells is vital to realising this, and through utilising new 'smart' materials such as conductive polymers we can provide a multi-pronged approach to supporting and stimulating the stem cells via engineered surface properties, electrical, and electromechanical stimulation. Here we present a fundamental study on the viability of cardiac progenitor cells on conductive polymer surfaces, focusing on the impact of surface properties such as roughness, surface energy, and surface chemistry with variation of the polymer dopant molecules. The conductive polymer materials were shown to provide a viable support for both endothelial and cardiac progenitor cells, while the surface energy and roughness were observed to influence viability for both progenitor cell types. Characterising the interaction between the cardiac progenitor cells and the conductive polymer surface is a critical step towards optimising these materials for cardiac tissue regeneration, and this study will advance the limited knowledge on biomaterial surface interactions with cardiac cells.

\section{Introduction}

A myocardial infarction (MI), commonly known as a heart attack, is the interruption of blood supply to a part of the heart, causing heart cells to die. MI causes fibrotic scar formation and impaired cardiac function, resulting in a reduced left ventricular ejection fraction (EF). ${ }^{1}$ Currently the most successful treatment to restore function is through by-pass surgery, and ultimately a cardiac transplantation is the only long-term solution. ${ }^{2}$ However, due to the shortage of organ donors and complications associated with immune suppressive treatments, development of new strategies to help regenerate the injured heart is necessary. ${ }^{3}$

Cardiac tissue engineering is a relatively new interdisciplinary approach to replace or repair diseased or dysfunctional cardiovascular tissues with vital structures that allow regeneration of host tissue. Surgical resection of nonviable myocardium after infarction and replacement with bioengineered grafts or insertion of a cardiac patch onto the damaged tissue may improve cardiac function and prevent heart failure. ${ }^{4}$ The stem cell niche microenvironment is a vital factor in tuning the

${ }^{a}$ Biosensors and Bioelectronics Centre, Dept. of Physics, Chemistry and Biology (IFM), Linköping University, Linköping 581 83, Sweden. E-mail: amy.gelmi@liu.se

${ }^{b}$ Integrative Regenerative Medicine Centre, Department of Clinical and Experimental Medicine, Linköping University, Linköping 581 85, Sweden

'Department of Biomedical Engineering, Linköping University, Linköping 581 85, Sweden

$\uparrow$ Electronic supplementary information (ESI) available: Data values provided. See DOI: $10.1039 / \mathrm{c} 4 \mathrm{tb} 00142 \mathrm{~g}$ stem cell differentiation. Electrical and mechanical stimulation have been shown to be important external stimuli to stem cell differentiation..$^{5-8}$ In fact, it has been reported that culture of mesenchymal stem cells (MSCs) on artificial matrices mimicking the mechanical properties of the brain, muscle, and bone resulted in the expression of lineage specific markers of the corresponding tissues at $50 \%$ of the levels induced by chemical differentiation. ${ }^{6}$

Conductive polymers (CPs) have been widely researched as biomaterials ${ }^{9,10}$ due to their inherent conductivity, relative softness compared to conventional conductive materials (i.e. metals), and ease of synthesis. ${ }^{11-15}$ Manipulation of synthesis parameters also offers fine control over the physical properties of the CPs, ${ }^{16,17}$ which is a useful tool in tuning the material for specific tissue engineering applications. Polypyrrole (PPy) is a promising $\mathrm{CP}$ for use in tissue engineering, ${ }^{18-21}$ and while there has been a strong focus on neural and muscle cell research, ${ }^{20,22-24}$ there has been less focus on cardiac tissue engineering. PPy has been shown to be compatible with cardiac cells, and its conductive nature demonstrated to be advantageous. Nishizawa et al. created PPy coated microelectrodes to demonstrate successful electrical stimulation of cardiac myocytes, with the myocyte sheet responding with synchronized beating. ${ }^{25}$ PPy has also been fabricated as a fibrous 3-dimensional scaffold for cell culture; 'fluffy' PPy scaffolds were reported to have greater cardiomyocyte differentiation compared to tissue culture plates. ${ }^{26}$

A secondary advantage of PPy is the polymer's ability to improve biocompatibility via incorporated dopants. Synthesising 
the polymer via electropolymerisation allows the incorporation of a negatively charged counterion, or dopant (Fig. 1).

The properties of the dopant (size, functional groups and charge distribution) will affect the physical properties of the polymer, such as Young's modulus, roughness, morphology, thickness, and wettability. ${ }^{16,20}$ These properties in turn will influence cell growth and viability. ${ }^{27-31}$ The dopants can also be used to enhance the biocompatibility of the polymer through the use of biomolecules. ${ }^{32}$

PPy is an electroactive material and can be used to release drug molecules, ${ }^{33,34}$ to electrically stimulate or record cell signalling ${ }^{35-37}$ and provide mechanical stimulation. ${ }^{38}$

The goal of this study is to evaluate the biocompatibility of PPy polymer surfaces using a range of different dopant molecules for two types of cardiac stem cells, and to expand the limited knowledge on how surface properties influence the viability of cardiac stem cells. In this paper we have used a large set of dopants, of which they are either inorganic, polyelectrolytes, or biomolecules, in order to assess how cardiac cells respond to the different dopants and which they show proclivity for. For example, the polysaccharides hyaluronic acid (HA) and chondroitin sulphate (CS) are components of the extracellular matrix and have been previously incorporated into PPy materials with the aim to improve biocompatibility. ${ }^{18,21,39}$ The semi-synthetic anticoagulant polysaccharide dextran sulphate (DS) is also similar in structure to HA and CS with a higher degree of sulfonation. Dopants such as dodecylbenzosulfonic acid (DBS), polystyrene sulfonate (PSS), and paratoluene sulfonic acid (pTS) are dopants commonly used in the preparation of PPy materials with good electroactive properties, such as high conductivity and stability. ${ }^{40-42}$ These dopants have also been shown to support cellular growth and are non-cytotoxic. ${ }^{20,38,43}$ The smaller inorganic dopants, ionic chloride (Cl) and perchlorate $\left(\mathrm{LiClO}_{4}\right)$, are well-known dopants for the preparation of PPy films, ${ }^{44}$ and have a lower molecular weight than the previously listed dopants, which will influence the material properties ${ }^{42,44}$.

The impact of material surface properties (e.g. topography and chemistry) on stem cell viability and their role in regulating stem cell differentiation have been reviewed by Deb et al. ${ }^{45}$ Most studies clearly demonstrated that both architectural and chemical cues had a significant impact on cell attachment, spreading, and differentiation. For example, Berry et al. ${ }^{46}$ studied the in vitro interaction of human fibroblast cells and primary human bone marrow cells with silicon oxide substrates

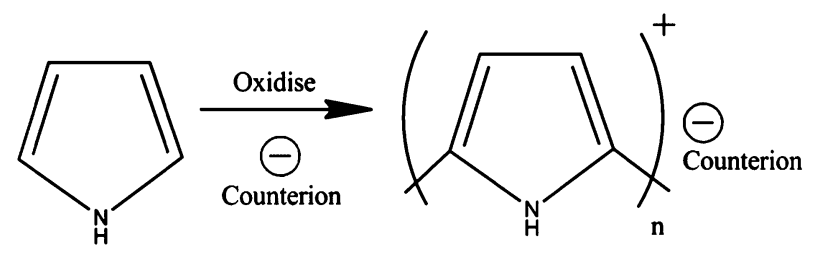

Fig. 1 Electropolymerisation of polypyrrole. Upon oxidising the monomer a negatively charged counterion is incorporated to balance the positive charge on the polymer backbone. grafted with poly-L-lysine-g-poly(ethylene glycol) (PLL-PEG). They reported that by changing the surface morphology using lithographic techniques, cell responses to substrates, which were chemically identical, were enhanced.

In another study, Bauer et al., (2009) ${ }^{47}$ suggested that mesenchymal stem cells were more influenced by the nanoscale surface topography of zirconium and titanium oxide $\mathrm{ZrO}_{2}$ and $\mathrm{TiO}_{2}$ ) nanotubes than their chemistry. It was observed that cell adhesion and spreading were enhanced for nanotube diameters of $15-30 \mathrm{~nm}$, while a strong decrease in cell activity was observed for diameters larger than $50 \mathrm{~nm}$, demonstrating that stem cells show a size-specific reaction to the nano-patterns. A more recent study by Shanmugasundaram $e t$ al. ${ }^{48}$ investigated the interaction of nano- to micron-size fibers with the human mesenchymal stem cells and their impact on chondrogenesis (cartilage formation). They showed that chondrogenesis was enhanced when micron-size fibers with larger pores were used.

As every individual cell type may respond differently when growing on a substrate we have used two cell lines to assess the performance of the conductive polymer materials as possible cardiac cell supports.

The cell types endothelial progenitor cells (EPCs) and cardiac progenitor cells (CPCs) are both important cells used in cardiac regeneration. EPCs have the potential to differentiate into endothelial cells, and to contribute to the vascularization of ischemic tissues. ${ }^{49}$ EPCs play a role in promoting angiogenesis, ${ }^{50,51}$ and have been applied to MI regeneration studies successfully. ${ }^{52,53}$

CPCs are resident cardiac stem cells with the ability to generate cardiomyocytes, smooth muscle, and endothelial cells. ${ }^{49,54}$ CPCs have the potential to differentiate into new functional cardiomyocytes to regenerate new cardiac tissue to heal the non-functional fibrotic scar tissue that results from an MI.

The physical properties of the PPy polymer surfaces will be measured to take into account the influence of surface properties such as roughness, surface energy, and morphology on cellular response. The cells will then be assessed for biocompatibility using the cell density and live-dead ratio. The conclusions of this study will be of vital importance for the further development of electroactive surfaces and coatings for the support and direction of cardiac stem cells using electrical and mechanical stimulation.

\section{Experimental}

\section{Polymer synthesis}

The PPy polymer was synthesized using electrochemical polymerization in a 3 point electrochemical cell using a $\mathrm{Ag} / \mathrm{AgCl}$ reference electrode (BASi, USA). A gold coated silicon wafer was cleaned with ethanol and DI water, then dried under $\mathrm{N}_{2}$ gas. An aqueous monomer solution of $0.1 \mathrm{M}$ pyrrole (Sigma-Aldrich) and $2 \mathrm{mg} \mathrm{ml}^{-1}$ of the selected dopant was prepared using DI water (Milli Q, $18 \mathrm{M} \Omega$ ). The dopant chemicals used were $\mathrm{NaCl}$ (Sigma-Aldrich), chondroitin sulfate A sodium salt (SigmaAldrich), dodecylbenzenesulfonic acid (TCI Europe), dextran sulphate sodium salt (Sigma-Aldrich), hyaluronic acid sodium 
salt (Sigma-Aldrich), lithium perchlorate (Fischer Scientific), poly(sodium 4-styrenesulfonate) (Sigma-Aldrich), and sodium para-toluenesulfonate (Sigma-Aldrich). The polymer was grown at a constant current density of $0.25 \mathrm{~mA} \mathrm{~cm}{ }^{-2}$ for 10 minutes using a Ivium CompactStat (Netherlands). Once electropolymerisation was complete the polymer films were washed with DI water and dried with $\mathrm{N}_{2}$ gas.

\section{Profilometry}

The roughness of the polymer films was measured using a Dektak 6M Profilometer (Veeco Instruments Inc., NY). A stylus force of $3 \mathrm{mg}$ was used to measure the roughness of three individual samples for each polymer(dopant) material.

\section{Contact angle goniometry}

The wettability of the polymer films was characterised using the Sessile Drop Technique with a CAM200 Optical Contact Angle Meter (KSV Instruments, Finland). The water contact angle was measured on three individual samples for each polymer(dopant) using Milli Q water (18 M $\Omega$ ).

\section{Scanning electron microscopy}

The Scanning Electron Microscopy (SEM) micrographs were taken using a Leo 1550 Gemini SEM operating at $5.02 \mathrm{keV}$. The samples were coated with a layer of gold via evaporation.

\section{CPC cell cultures}

CPCs were isolated from the hearts of adult mice using a cardiac stem cell isolation kit (Millipore), according to the manufacturer's protocol. The maintenance medium used was Dulbecco's Modified Eagle Medium: Nutrient Mixture F-12 (DMEM/F12) (Sigma-Aldrich) supplemented with 10\% FCS, $1 \%$ penicillin-streptomycin (Invitrogen), $1 \times$ Insulin-Transferrin-Selenium (ITS) (Invitrogen), 0.5\% DMSO (Sigma-

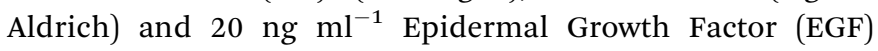
(Invitrogen).

\section{Late outgrowth EPC cell cultures}

EPCs were isolated from peripheral blood of healthy blood donors, using density gradient centrifugation. Mononuclear cells (MNCs) were separated using Histopaque ${ }^{\circledR}-1077$ HybriMax $^{\mathrm{TM}}$ (Sigma-Aldrich) according to the manufacturer's protocol. Purified MNCs were plated on collagen type I coated 6well plates in complete EGM-2 medium (Lonza) with $10 \%$ FCS at a density of $1.5 \times 10^{7}$ cells per well. After 4 days, non-adherent cells were removed and the medium was changed daily for the first week and every other day the following weeks. After 3-4 weeks endothelial cell colonies appeared. The EPCs were passed onto gelatin-coated cell culture flasks and further expanded.

\section{Preparation of biomaterials for cell culture}

All samples were incubated overnight in $5 \times$ concentrated penicillin-streptomycin solution followed by thorough washing with sterile PBS. The materials were then incubated for $24 \mathrm{~h}$ in sterile antibiotic-free medium to check the efficacy of the bacterial decontamination. If no microbial growth was observed, the samples were used for cell culture testing.

\section{Cell culture assays}

All decontaminated biomaterial samples were placed at the bottom of a 6-well cell culture plate and $3 \mathrm{ml}$ of the appropriate cell maintenance medium was added. The maintenance medium used was Dulbecco's Modified Eagle Medium: Nutrient Mixture F-12 (DMEM/F12) (Sigma-Aldrich) supplemented with 10\% FCS, 1\% penicillin-streptomycin (Invitrogen), $1 \times$ InsulinTransferrin-Selenium (ITS) (Invitrogen), 0.5\% DMSO (SigmaAldrich) and $20 \mathrm{ng} \mathrm{ml}^{-1}$ Epidermal Growth Factor (EGF) (Invitrogen). Cells were collected by trypsinization and seeded at a density of $2 \times 104$ and $5 \times 104$ cells per well for EPCs and CPCs, respectively. The same amount of cells was also seeded in empty wells for the CPCs and gelatin-coated wells for the EPCs and these served as controls. Once the control wells became confluent, after approximately 3 days of culture, all wells were stained with the LIVE/DEAD® Viability/Cytotoxicity assay (Invitrogen) according to the standard protocol. The stained cells were photographed with a Zeiss inverted fluorescent microscope using the Zen software (Zeiss). For every field, green and red fluorescence, corresponding to live and dead cells respectively, was documented under a $10 \times$ magnification.

\section{Cell analysis}

Cell numbers were quantified using the cell count function in ImageJ (NIH). At least 2 fields were counted per sample. Statistical analysis was performed using 1-way ANOVA and Student's $t$-test (two tail). Representation of significance is denoted: $* p<0.01$.

\section{Results and discussion}

\section{Surface characterisation}

The roughness of the polymers was measured via profilometry and was observed to vary depending on the dopant (Fig. 2, bottom).

The polymer $\mathrm{PPy}\left(\mathrm{LiClO}_{4}\right)$ was considerably rougher than the rest of the materials $(1087 \pm 155 \mathrm{~nm})$, an observation reflected in the SEM micrographs of the material. The dopants CS, DS, pTS, and PSS produced materials with low roughness values $(<24 \mathrm{~nm})$ comparatively. $\mathrm{PPy}(\mathrm{Cl})$ produced a higher roughness value than these dopants $(54 \pm 13 \mathrm{~nm})$, due to the larger, distinct nodular surface morphology. PPy(HA) had a high roughness value of $159 \pm 26 \mathrm{~nm}$, of which the wrinkle structures observed in the SEM micrographs would have contributed to. The thickness of these polymer materials is of the range of 200$300 \mathrm{~nm}$, grown under the same synthesis parameters as described by Gelmi et al. ${ }^{16}$

The water contact angle of the polymer materials was observed to vary within a range of values from $19.7 \pm 0.2^{\circ}$ for $\mathrm{PPy}(\mathrm{Cl})$ to $72.4 \pm 0.6^{\circ}$ for PPy(pTS) (Fig. 2, top). All of the materials demonstrate hydrophilicity, with PPy(pTS) being the least hydrophilic of the set. 


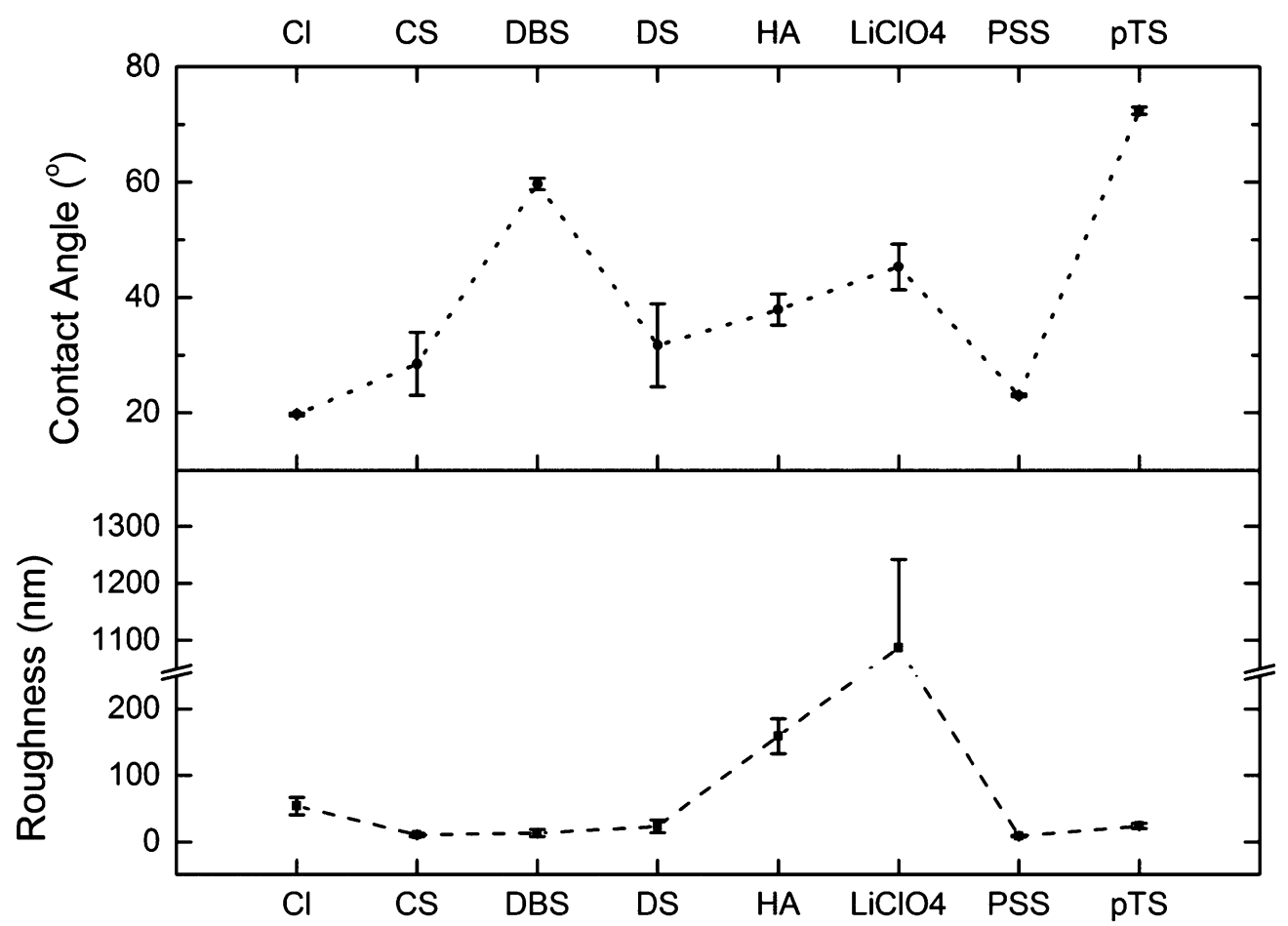

Fig. 2 Contact angle (top) and roughness (bottom) values for each PPy(dopant) material. Error bars are standard errors. $\dagger$

The surface of the PPy-dopant materials was analysed using SEM. The surface structure for the polymers shows the typical 'cauliflower' structure of PPy. The dopants CS, DBS, and DS produce polymer films with a uniformly smooth surface (Fig. 3A(i) and B(i)), compared to the irregularly structured surfaces of the films synthesized with $\mathrm{LiClO}_{4}$ (Fig. $3 \mathrm{C}(\mathrm{i})$ ), PSS, and pTS. PPy(Cl) has a uniform surface of distinct $\sim 500 \mathrm{~nm}$ nodular structures. PPy(HA) shows the nodular structure but the overall surface topography is dominated by 'wrinkles' of the polymer surface, an effect which is the result of the polymer drying after synthesis.

\section{Cell culture and biocompatibility}

Fluorescent images of the CPCs on the polymer materials were obtained to determine the ratio of live cells to dead, and to calculate the cell density for each polymer(dopant) (Fig. 3).

The live-dead ratio, Fig. 4a, demonstrates that all of the materials have over $94 \%$ of EPCs alive 3 days post-seeding in culture. Compared to the rest of the polymer(dopant) materials, $\operatorname{PPy}\left(\mathrm{LiClO}_{4}\right)$ and PPy(HA) had the lowest CPC live-dead ratio. The rest of the materials all have over $96 \%$ of the CPCs alive after the 3 days of culture.

The EPC density values on the polymers, Fig. $4 \mathrm{~b}$, show that PPy(CS), PPy(DBS), PPy(DS), and PPy(pTS) do not have a significantly different cell density to that of the control sample, a standard polystyrene cell culture plate. $\mathrm{PPy}\left(\mathrm{LiClO}_{4}\right), \mathrm{PPy}(\mathrm{HA})$, and PPy(PSS) have a lower cell density than that of the control, and for $\mathrm{PPy}(\mathrm{Cl})$ the cell density is significantly lower than that of the control.
The CPC density values, Fig. 4b, show that for the exception of $\mathrm{PPy}\left(\mathrm{LiClO}_{4}\right)$ the polymer(dopant) materials do not have a significantly different cell density to that of the control sample.

\section{Cell viability and response to physical properties}

The EPCs showed very high live cell ratios on all the polymer samples, indicating that all the polymer(dopant) materials are able to support the EPCs and are biocompatible. For most polymer(dopant) materials the CPC live cell ratio was very high, indicating good biocompatibility. However, for PPy(HA) and $\mathrm{PPy}\left(\mathrm{LiClO}_{4}\right)$ the much lower live cell ratio indicates that these polymers are not the optimal materials for CPC growth.

The roughness of the polymer appears to have an influence on the viability of the CPCs; the high roughness of the polymers $\operatorname{PPy}\left(\mathrm{LiClO}_{4}\right)$ and PPy $(\mathrm{HA})$ correlated with a low percentage of live CPCs. This high roughness is also reflected in the surface morphology of these polymers in the SEM micrographs (Fig. 3 $\mathrm{C}(\mathrm{i})$ ). The surface of the $\mathrm{PPy}(\mathrm{HA})$ material has large 'wrinkles', approximately $1 \mu \mathrm{m}$ in width. These 'wrinkles' may not exist during the in vitro studies as they are most likely an artifact produced by the drying of the polymer. PPy $(\mathrm{HA})$ has been observed to be hydrogel-like, ${ }^{55}$ hence when in an aqueous solution the polymer will reabsorb water and swell. The irregular surface of the $\mathrm{PPy}(\mathrm{LiClO})_{4}$, with approximately $1 \mu \mathrm{m}$ diameter nodules, may also contribute to the reduced viability of these surfaces. Poor neural stem cell viability on $\mathrm{PPy}\left(\mathrm{LiClO}_{4}\right)$ has been noticed before. ${ }^{14,56}$ The dopant HA, as a biological molecule present in the ECM, is also not expected to be toxic to living cells but has a history of producing poor viability PPy materials. ${ }^{20,39}$ 
SEM

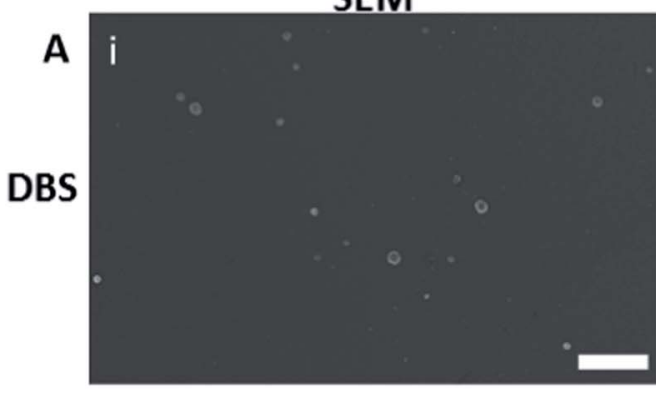

B

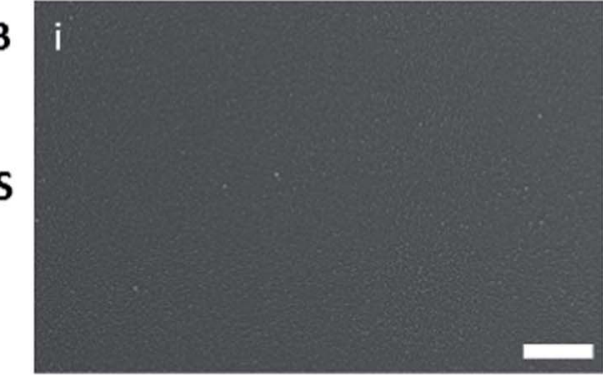

C

C i

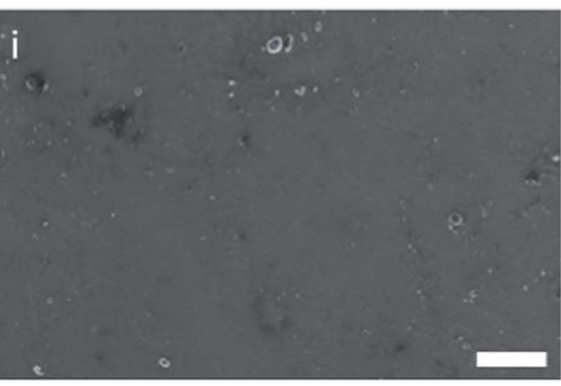

EPC
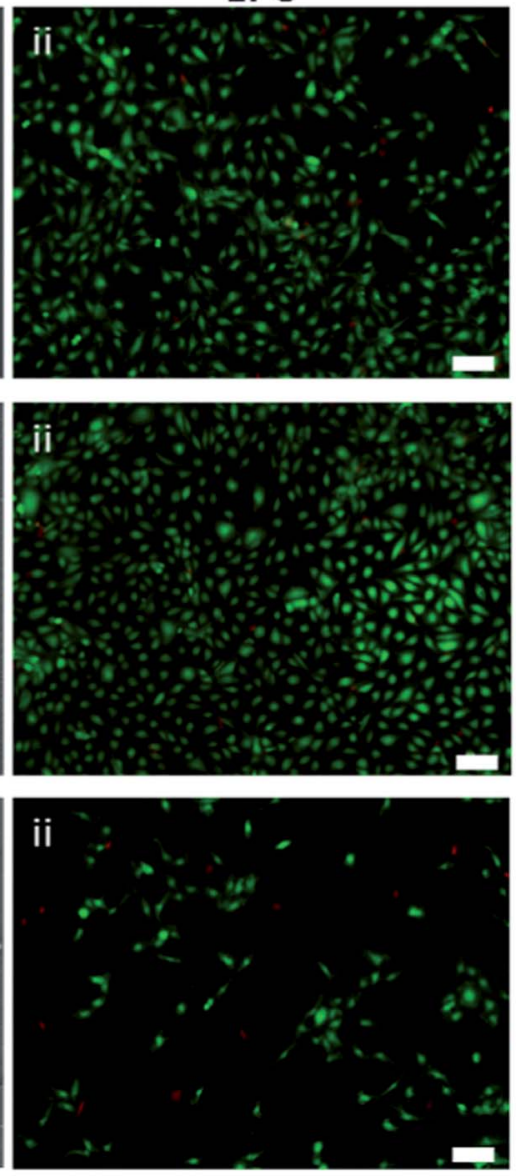

CPC
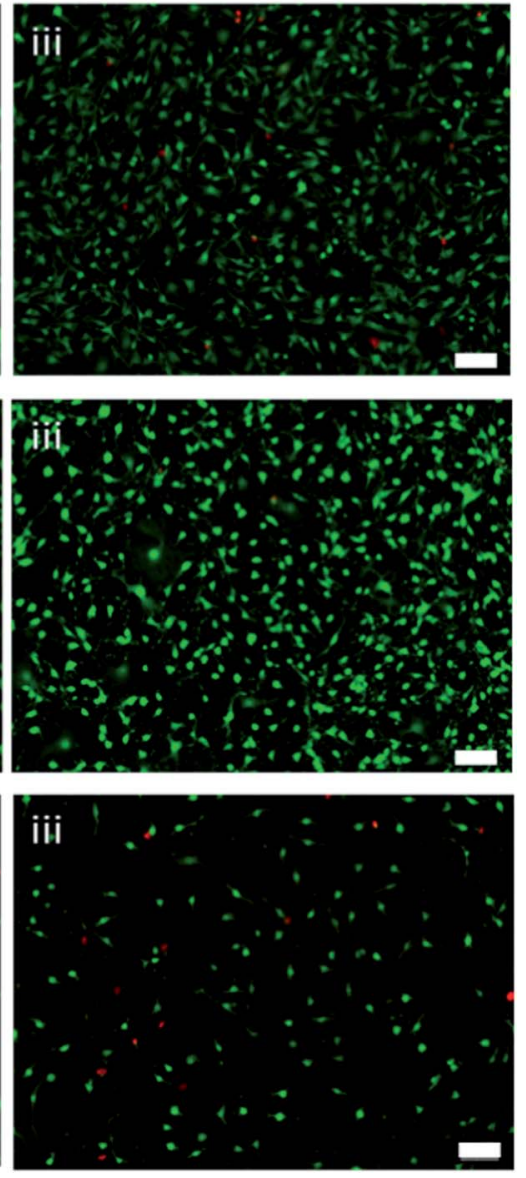

Fig. 3 Comparison of PPy materials (A) PPy(DBS), (B) CS, and (C) $\mathrm{LiClO}_{4}$ with (i) SEM micrograph (scale bar $10 \mu \mathrm{m}$ ), (ii) live-dead stain of EPC (scale bar $50 \mu \mathrm{m}$ ) and (iii) live-dead stain of CPC (scale bar $50 \mu \mathrm{m}$ ).
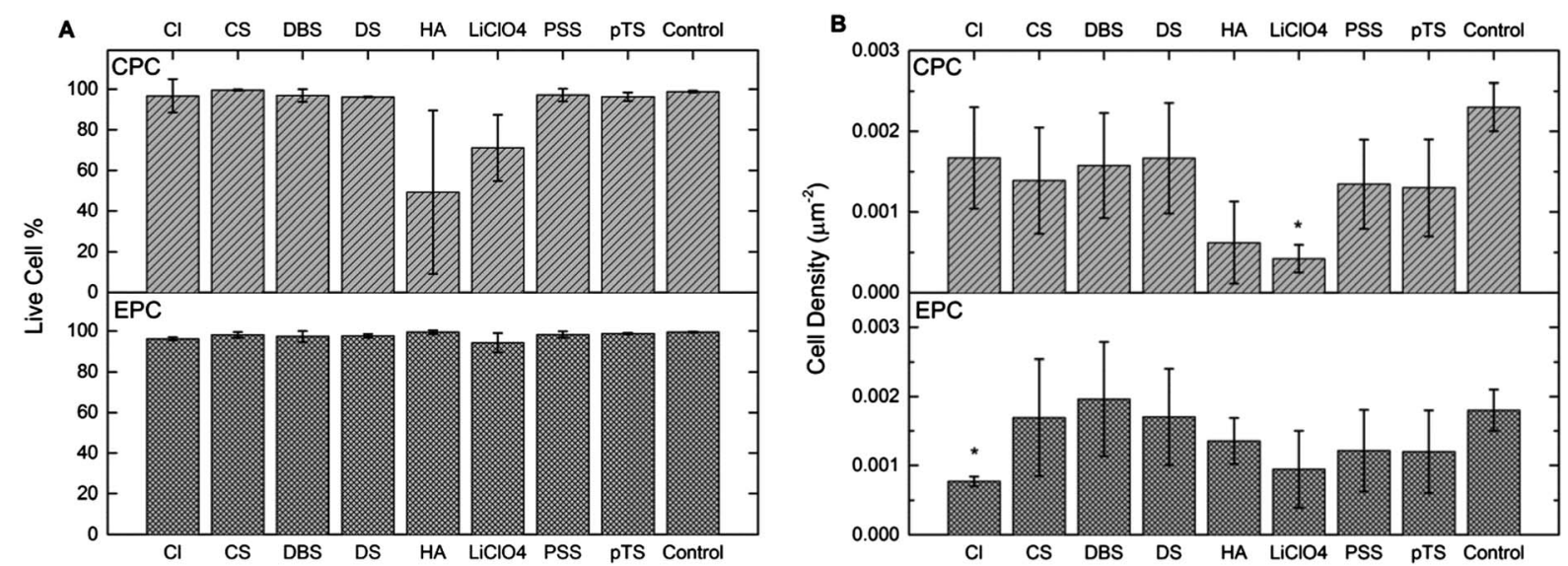

Fig. 4 (a) Cell live-dead ratio values for each PPy(dopant) material for CPC (top) and ECP (bottom). (b) Cell density values for each PPy(dopant) material for CPC (top) and ECP (bottom). Errors are standard errors. * $p<0.05$.

The reduced EPC and CPC cells' viability and density on the rougher surface of $\mathrm{PPy}\left(\mathrm{LiClO}_{4}\right)$, compared to other materials, is also in line with the previous work of Bauer et al. ${ }^{47}$ They had reported that MSCs grew better on smoother surfaces with a nanofiber size smaller than $15 \mathrm{~nm}$ compared to nanofiber sizes of $50 \mathrm{~nm}$ and larger (normally, the larger the nanofiber size the rougher is the surface of the nanofiber scaffolds). In addition, factors such as dopant toxicity and poor initial cellular adhesion may also contribute to the poor viability on $\operatorname{PPy}\left(\mathrm{LiClO}_{4}\right)$. 
The EPCs show no significant sensitivity to changes in roughness of the polymers. The hydrophilicity of the polymer materials does not correlate with the surface roughness, leading to a range of contact angle values corresponding with low roughness values for the majority of the materials. No direct relationship between surface energy and cell density was observed for either CPCs or EPCs.

Conversely, the CPCs display a sensitivity to the surface roughness of the materials. $\mathrm{PPy}(\mathrm{Cl})$ and $\mathrm{PPy}(\mathrm{pTS})$ have a difference of $\Delta 52.7 \pm 0.8^{\circ}$ in their contact angle values and have similar CPC density values $\left(1.7 \pm 0.7 \times 10^{-4} \mu \mathrm{m}^{-2}\right.$ and $1.7 \pm 0.6$ $\times 10^{-4} \mu \mathrm{m}^{-2}$ respectively). The high roughness values of PPy(HA) and PPy $\left(\mathrm{LiClO}_{4}\right)$ appear to have a strong influence on the CPC density, as the values are lower than the rest of the materials used.

\section{Cell response to dopants}

The polymer PPy $(\mathrm{Cl})$ had the lowest EPC density value $(7.7 \pm 0.7$

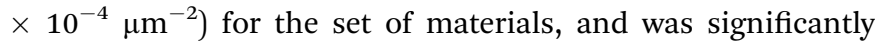
lower than the control surface. The roughness and contact angle measurements for this material are significantly different from some of other dopants used in this study (i.e. CS, DBS, PSS). This suggests that leeching of the dopant during the cell incubation might have had a detrimental effect on the cell population. $\mathrm{As} \mathrm{Cl}^{-}$is a much smaller dopant than the rest used in this study, the ions can move out of the polymer in solution while the larger dopants (DBS, CS, DS, HA, and PSS) will not leech from the polymer.

The polymers PPy(CS) and PPy(PSS) were measured to have similar roughness and contact angle values, and both resulted in non-significantly different cell densities for EPCs and CPCs. The biomolecule CS is a component of the extracellular matrix, while PSS is a large polyelectrolyte; the cells however displayed no preference for the biologically doped polymer. The biological dopant HA produced largely poor results for CPC cell density, correlating with an extremely rough surface. While HA and CS are very similar in structure, ${ }^{\mathbf{1 6}}$ the corresponding changes in polymer physical properties provided a much greater influence on the CPCs than any possible (bio-) chemical influence from the presence of the dopant.

Therefore, both the CPCs and EPCs show no significant preference for the ECM doped polymers over the non-biological dopants used in this study. While some studies previously showed in the literature that the incorporation of such ECM dopants do result in specific binding sites for integrin-cell intermediate proteins such as fibronectin, ${ }^{32}$ other studies confirm that non-biological dopants result in good viability too. ${ }^{14,38,57}$ It seems the overall surface properties of these polymers appear to have a stronger influence on cell viability than the biological or non-biological nature of the dopant. The variations in cell viability and density are likely due to the multifactorial nature of cell-biomaterial interactions. It is well-understood that such interactions are governed by multifaceted parameters including chemical properties (composition, surface energy, etc.) and physical properties (roughness, porosity, etc.) of biomaterials as well as cells' biological characteristics.

\section{Conclusions}

In conclusion, the success of the PPy substrates for cardiac stem cell support was directly influenced by the physical properties of the materials. While all PPy(dopant) materials provided a nontoxic environment for the cells to adhere and survive, CPCs showed a sensitivity to high surface roughness. Further studies will investigate the change of the physical properties of a polymer(dopant) material via synthesis parameters to fully separate the influence of the dopant and physical properties. Neither cell type showed any preference for the biologically doped polymers, with surfaces of similar physical properties displaying the same cell densities for both biological and non-biological dopants. These results will be vital in determining which polymer materials to move forward with in the investigation of electrical and mechanical stimulus of cardiac stem cells using electroactive polymers.

\section{Acknowledgements}

We would like to acknowledge Prof. May Griffith and Linköping Integrative Regenerative Medicine Centre (IGEN), Linköping University, for the supply of the progenitor cells and cell facilities. Prof. Anthony Turner is acknowledged for his support. Financial support was received from Linköping University, IGEN (post-doc grant), COST-Action MP1003, Knut och Alice Wallenberg Commemorative Fund, and the European Research Agency for EU FP7-PEOPLE-2011-CIG-Marie Curie ActionsCareer Integration Grant (CIG).

\section{References}

1 P. Pascale, P. Taffe, C. Regamey, L. Kappenberger and M. Fromer, Reduced Ejection Fraction After Myocardial Infarction is it Sufficient to Justify Implantation of a Defibrillator?, Chest, 2005, 128, 2626-2632.

2 J. Leor, S. Aboulafia-Etzion, A. Dar, L. Shapiro, I. M. Barbash, A. Battler, et al. Bioengineered Cardiac Grafts: A New Approach to Repair the Infarcted Myocardium?, Circulation, 2000, 102, Iii-56-Iii-61.

3 P. Zammaretti and M. Jaconi, Cardiac tissue engineering: regeneration of the wounded heart, Curr. Opin. Biotechnol., 2004, 15, 430-434.

4 J. Leor, S. Aboulafia-Etzion, A. Dar, L. Shapiro, I. M. Barbash, A. Battler, et al. Bioengineered Cardiac Grafts: A New Approach to Repair the Infarcted Myocardium?, Circulation, 2000, 102, III-56-III-61.

5 E. Ghafar-Zadeh, J. R. Waldeisen and L. P. Lee, Engineered approaches to the stem cell microenvironment for cardiac tissue regeneration, Lab Chip, 2011, 11, 3031-3048.

6 D. Li, J. Zhou, F. Chowdhury, J. Cheng, N. Wang and F. Wang, Role of mechanical factors in fate decisions of stem cells, Regener. Med., 2011, 6, 229-240.

7 J. Guan, F. Wang, Z. Li, J. Chen, X. Guo, J. Liao, et al. The stimulation of the cardiac differentiation of mesenchymal stem cells in tissue constructs that mimic myocardium 
structure and biomechanics, Biomaterials, 2011, 32, 55685580.

8 I. Titushkin, S. Sun, J. Shin and M. Cho, Physicochemical Control of Adult Stem Cell Differentiation: Shedding Light on Potential Molecular Mechanisms, J. Biomed. Biotechnol., 2010, 2010, 1-14.

9 D. D. Ateh, H. A. Navsaria and P. Vadgama, Polypyrrole-based conducting polymers and interactions with biological tissues, J. R. Soc., Interface, 2006, 3, 741-752.

10 A.-D. Bendrea, L. Cianga and I. Cianga, Review paper: Progress in the Field of Conducting Polymers for Tissue Engineering Applications, J. Biomater. Appl., 2011, 26, 3-84.

11 N. Guimard, N. Gomez and C. Schmidt, Conducting polymers in biomedical engineering, Prog. Polym. Sci., 2007, 32, 876-921.

12 R. A. Green, N. H. Lovell, G. G. Wallace and L. A. PooleWarren, Conducting polymers for neural interfaces: Challenges in developing an effective long-term implant, Biomaterials, 2008, 29, 3393-3399.

13 K. Svennersten, M. H. Bolin, E. W. H. Jager, M. Berggren and A. Richter-Dahlfors, Electrochemical modulation of epithelia formation using conducting polymers, Biomaterials, 2009, 30, 6257-6264.

14 V. Lundin, A. Herland, M. Berggren, E. W. H. Jager and A. I. Teixeira, Control of Neural Stem Cell Survival by Electroactive Polymer Substrates, Plos One, 2011, 6, e18624.

$15 \mathrm{~J}$. Y. Wong, R. Langert and D. E. Ingberi, Electrically conducting polymers can noninvasively control the shape and growth of mammalian cells, Science, 1994, 91, 32013204.

16 A. Gelmi, M. J. Higgins and G. G. Wallace, Physical surface and electromechanical properties of doped polypyrrole biomaterials, Biomaterials, 2010, 31, 1974-1983.

17 G. Tourillon and F. Garnier, Effect of dopant on the physicochemical and electrical properties of organic conducting polymers, J. Phys. Chem., 1983, 87, 2289-2292.

18 J. H. Collier, J. P. Camp, T. W. Hudson and C. E. Schmidt, Synthesis and characterization of polypyrrole - hyaluronic acid composite biomaterials for tissue engineering applications, J. Biomed. Mater. Res., 1999, 50, 574-584.

19 B. Garner, a. Georgevich, a. J. Hodgson, L. Liu and G. G. Wallace, Polypyrrole-heparin composites as stimulusresponsive substrates for endothelial cell growth, $J$. Biomed. Mater. Res., 1999, 44, 121-129.

20 K. J. Gilmore, M. Kita, Y. Han, A. Gelmi, M. J. Higgins, S. E. Moulton, et al. Skeletal muscle cell proliferation and differentiation on polypyrrole substrates doped with extracellular matrix components, Biomaterials, 2009, 30, 5292-5304.

21 J. S. Moreno, S. Panero, M. Artico and P. Filippini, Synthesis and characterization of new electroactive polypyrrole chondroitin sulphate A substrates, Bioelectrochemistry, 2008, 72, 3-9.

22 C. Schmidt, T. Rivers, T. Hudson and J. Collier, Modification of electroactive biomaterials for neural engineering applications, Conducting Polymers and Polymer Electrolytes: from Biology to Photovoltaics, 2003, vol. 832, pp. 154-165.
23 B. C. Thompson, R. T. Richardson, S. E. Moulton, A. J. Evans, S. O'Leary, G. M. Clark, et al. Conducting polymers, dual neurotrophins and pulsed electrical stimulation Dramatic effects on neurite outgrowth, J. Controlled Release, 2010, 141, 161-167.

24 A. S. Rowlands and J. J. Cooper-White, Directing phenotype of vascular smooth muscle cells using electrically stimulated conducting polymer, Biomaterials, 2008, 29, 4510-4520.

25 M. Nishizawa, H. Nozaki, H. Kaji, T. Kitazume, N. Kobayashi, T. Ishibashi, et al. Electrodeposition of anchored polypyrrole film on microelectrodes and stimulation of cultured cardiac myocytes, Biomaterials, 2007, 28, 1480-1485.

26 L. Jin, T. Wang, Z.-Q. Feng, M. Zhu, M. K. Leach, Y. I. Naime, et al. Fabrication and characterization of a novel fluffy polypyrrole fibrous scaffold designed for 3D cell culture, $J$. Mater. Chem., 2012, 22, 18321-18326.

27 A. P. Balgude, X. Yu, A. Szymanski and R. V. Bellamkonda, Agarose gel stiffness determines rate of DRG neurite extension in 3D cultures, Biomaterials, 2001, 22, 1077-1084.

28 A. J. Engler, M. A. Griffin, S. Sen, C. G. Bönnemann, H. L. Sweeney and D. E. Discher, Myotubes differentiate optimally on substrates with tissue-like stiffness: pathological implications for soft or stiff microenvironments, Cell Biol., 2004, 166, 877-887.

29 K. Keiswetter, Z. Schwartz, T. W. Hummert, D. L. Cochran, J. Simpson, D. D. Dean, et al. Surface roughness modulates the local production of growth factors and cytokines by osteoblast-like MG-63 cells, Biomed. Mater., 1996, 32, 55-63.

$30 \mathrm{~J}$. Y. Wong, J. B. Leach and X. Q. Brown, Balance of chemistry, topography, and mechanics at the cell biomaterial interface: issues and challenges for assessing the role of substrate mechanics on cell response, Surf. Sci., 2004, 570, 119-133.

31 P. B. V. Wachem, A. H. Hogt, T. Beugeling, J. Feijin, A. Bantjes, J. Detmers, et al. Adhesion of cultured human endothelial cells onto methacrylate polymers with varying surface wettability and charge, Cell, 1987, 8, 323-328.

32 A. Gelmi, M. J. Higgins and G. G. Wallace, Resolving SubMolecular Binding and Electrical Switching Mechanisms of Single Proteins at Electroactive Conducting Polymers, Small, 2013, 9, 393-401.

33 B. Zinger and L. L. Miller, Timed release of chemicals from polypyrrole films, J. Am. Chem. Soc., 1984, 106, 6861-6863.

34 R. Wadhwa, C. F. Lagenaur and X. T. Cui, Electrochemically controlled release of dexamethasone from conducting polymer polypyrrole coated electrode, J. Controlled Release, 2006, 110, 531-541.

35 X. Cui and D. C. Martin, Fuzzy gold electrodes for lowering impedance and improving adhesion with electrodeposited conducting polymer films, Sens. Actuators, A, 2003, 103, 384-394.

36 K. A. Ludwig, J. D. Uram, J. Yang, D. C. Martin and D. R. Kipke, Chronic neural recordings using silicon microelectrode arrays electrochemically deposited with a poly(3,4-ethylenedioxythiophene) (PEDOT) film, J. Neural Eng., 2006, 3, 59-70. 
37 M. H. Bolin, K. Svennersten, X. J. Wang, I. S. Chronakis, A. Richter-Dahlfors, E. W. H. Jager, et al. Nano-fiber scaffold electrodes based on PEDOT for cell stimulation, Sens. Actuators, B, 2009, 142, 451-456.

38 K. Svennersten, M. Berggren, A. Richter-Dahlfors and E. W. H. Jager, Mechanical stimulation of epithelial cells using polypyrrole microactuators, Lab Chip, 2011, 11, 3287-3293.

39 J. Serra Moreno, S. Panero, S. Materazzi, A. Martinelli, M. G. Sabbieti, D. Agas, et al. Polypyrrole-polysaccharide thin films characteristics: electrosynthesis and biological properties, J. Biomed. Mater. Res., Part A, 2009, 88, 832-840.

40 L. F. Warren and D. P. Anderson, Polypyrrole Films from Aqueous Electrolytes: The Effect of Anions upon Order, $J$. Electrochem. Soc., 1987, 134, 101-105.

41 D.-h. Han, H. J. Lee and S.-m. Park, Electrochemistry of conductive polymers XXXV: Electrical and morphological characteristics of polypyrrole films prepared in aqueous media studied by current sensing atomic force microscopy, Electrochim. Acta, 2005, 50, 3085-3092.

42 J. M. Fonner, L. Forciniti, H. Nguyen, J. D. Byrne, Y.-f. Kou, J. Syeda-nawaz, et al. Biocompatibility implications of polypyrrole synthesis techniques, Biomed. Mater., 2008, 3, 1-12.

43 B. C. Thompson, S. E. Moulton, R. T. Richardson and G. G. Wallace, Effect of the dopant anion in polypyrrole on nerve growth and release of a neurotrophic protein, Biomaterials, 2011, 32, 3822-3831.

44 T. Silk, Q. Hong, J. Tamm and R. G. Compton, AFM studies of polypyrrole film surface morphology I. The influence of film thickness and dopant nature, Synth. Met., 2000, 93, 59-64.

45 K. D. Deb, M. Griffith, E. Muinck and M. Rafat, Nanotechnology in stem cells research: advances and applications, Front. Biosci., 2011, 17, 1747-1760.

46 C. Berry, A. Curtis, R. Oreffo, H. Agheli and D. Sutherland, Human fibroblast and human bone marrow cell response to lithographically nanopatterned adhesive domains on protein rejecting substrates, IEEE Transactions on NanoBioscience, 2007, 6, 201-209.

47 S. Bauer, J. Park, J. Faltenbacher, S. Berger, K. von der Mark and P. Schmuki, Size selective behavior of mesenchymal stem cells on $\mathrm{ZrO}_{2}$ and $\mathrm{TiO}_{2}$ nanotube arrays, Integr. Biol., 2009, 1, 525-532.

48 S. Shanmugasundaram, H. Chaudhry and T. L. Arinzeh, Microscale versus nanoscale scaffold architecture for mesenchymal stem cell chondrogenesis, Tissue Eng., Part A, 2010, 17, 831-840.

49 J.-P. Karam, C. Muscari and C. N. Montero-Menei, Combining adult stem cells and polymeric devices for tissue engineering in infarcted myocardium, Biomaterials, 2012, 33, 5683-5695.

50 K. Jujo, M. Ii and D. W. Losordo, Endothelial progenitor cells in neovascularization of infarcted myocardium, J. Mol. Cell. Cardiol., 2008, 45, 530-544.

51 P. P. Young, D. E. Vaughan and A. K. Hatzopoulos, Biologic Properties of Endothelial Progenitor Cells and Their Potential for Cell Therapy, Prog. Cardiovasc. Dis., 2007, 49, 421-429.

52 D. A. Narmoneva, R. Vukmirovic, M. E. Davis, R. D. Kamm and R. T. Lee, Endothelial Cells Promote Cardiac Myocyte Survival and Spatial Reorganization, Implications for Cardiac Regeneration, Circulation, 2004, 110, 962-968.

53 B. Assmus, V. Schächinger, C. Teupe, M. Britten, R. Lehmann, N. Döbert, et al. Transplantation of Progenitor Cells and Regeneration Enhancement in Acute Myocardial Infarction (TOPCARE-AMI), Circulation, 2002, 106, 3009-3017.

54 A. P. Beltrami, L. Barlucchi, D. Torella, M. Baker, F. Limana, S. Chimenti, et al. Adult cardiac stem cells are multipotent and support myocardial regeneration, Cell, 2003, 114, 763776.

55 J. A. Burdick and G. D. Prestwich, Hyaluronic Acid Hydrogels for Biomedical Applications, Adv. Mater., 2011, 23, H41-H56.

56 C. Salto, E. Saindon, M. Bolin, A. Kanciurzewska, M. Fahlman, E. W. H. Jager, et al. Control of neural stem cell adhesion and density by an electronic polymer surface switch, Langmuir, 2008, 24, 14133-14138.

57 C. E. Schmidt, V. R. Shastri, J. P. Vacanti and R. Langer, Stimulation of neurite outgrowth using an electrically conducting polymer, Proc. Natl. Acad. Sci. U. S. A., 1997, 94, 8948-8953. 